\title{
'Brexit' y los animales. El legado del Reino Unido al Derecho Animal
}

Keywords: Brexit; Reino Unido; Unión Europea; Bienestar Animal

La perplejidad de los británicos ante la decisión de dejar de ser parte de la UE, lo que se viene identificando como "Brexit", es comparable a la que nos asalta a quienes nos dedicamos al Derecho Animal ante dicha decisión.

El Reino Unido (UK) se ha distinguido desde hace siglos, por dotar de protección a los animales dentro del ámbito jurídico. La contribución, así mismo, de los británicos a la ética animal y a la creación de comportamientos integradores de los animales en la sociedad, no puede ser desdeñada. Por muchas razones, que pueden ir desgranándose de forma singular, puede afirmarse que los animales y los que defendemos a los animales, nos quedamos huérfanos sin Gran Bretaña en la Unión Europea.

La primera ley de protección animal se promulgó, precisamente en Gran Bretaña, en 1822. El Parlamento aprobó la Ley de Richard Martin para prevenir el trato cruel e inapropiado del ganado (Richard Martin's Act to

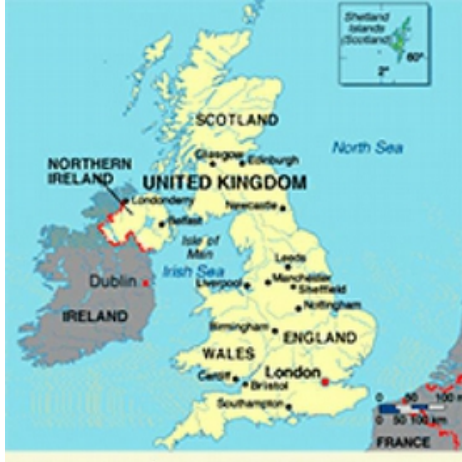

Imagen cortesía de "Project Britain" Prevent the Cruel and Improper Treatment of Cattle). Casi un siglo después, en 1911, se promulgó la Ley de Protección de los Animales (Animal Protection's Act) que se mantuvo en vigor, relativamente intacta, durante décadas, hasta que fue sustituida en 2006 por la ley de Bienestar Animal (Animal Welfare Act), que, por primera vez, impone a los dueños de animales de compañía el deber de cuidado de los mismos ("duty of care").

La novedad de esta fórmula legal estriba en que los dueños de animales de compañía, no sólo están obligados por ley a satisfacer las necesidades básicas de sus animales de compañía como el agua o el alimento, sino que la ley impone, además, la obligación de atención veterinaria y la de procurarles vivir en un entorno adecuado a sus necesidades, lo que, en la ley de 1911 sólo se refería a los animales de granja.

Si pensamos que muchas de estas leyes van acompañadas de un "Código de prácticas" (Codes of practice), podemos entender que la eficacia de éstas y otras leyes radica en que, el Código de prácticas hace asequible el entendimiento de la normativa legal al público al que va destinada. Es una guía práctica para poder aplicar mejor la ley y hacerla entendible a quienes resultan vinculados por ella. En tema de animales, es especialmente importante, por cuanto permiten detallar la responsabilidad de prestar, p.e., la necesaria atención veterinaria a los animales a lo largo de toda su vida. Mientras que la violación de un Código de prácticas no hace que una persona sea responsable en virtud de la ley relativa, la violación de un Código de prácticas puede, sin embargo, ser invocada para establecer la responsabilidad, por ejemplo en caso de maltrato animal por causar un sufrimiento o dolor innecesario ("unnecessary pain and suffering")[1] .

En el aspecto legal, la UE debe al Reino Unido algo tan importante como la creación del término científico "Bienestar Animal" (Animal Welfare), la forma de aplicación del mismo a través de las llamadas cinco libertades ("Five Freedoms") y, en las últimas décadas, la inclusión del término "sentient beings" (seres sentientes)[2] como estándar de tratamiento de los animales, a los que se les reconoce su 
capacidad no sólo de experimentar dolor físico, sino sufrimiento, pero también placer y diversión. Es decir, la legislación de los últimos 40 años de la UE respecto de los animales (granja, experimentación, transporte, espectáculos)[3] , no se entendería sin la decisiva intervención y creatividad del Reino Unido.

En la web del Gobierno del Reino Unido, pueden consultarse qué pautas de tratamiento deben seguir los responsables (no se les denomina propietarios!) de explotaciones ganaderas, expuestas de forma muy clara bajo la premisa de que: "si Ud. es el responsable de un animal de granja asegúrese bien de que lo cuida de forma apropiada" (If you're responsible for a farm animal you must make sure that you care for it properly). No es un simple enunciado amable, sino la consecuencia de años de cultura del bienestar animal, de estudio riguroso y de divulgación. No en vano los dos principales partidos políticos del Reino Unido, llevan y publican en sus programas qué normas piensan seguir en tema de Bienestar animal, tanto los conservadores bajo el eslogan "Los animales tienen amigos" (Animals have friends), como los laboristas, con el eslogan: "seis cosas que Ud. tiene que saber sobre los planes de los laboristas para proteger a los animales" (Six Things you need to know about Labour's plans to protect animals).

En efecto, en la creación de los actuales parámetros por los que se rige el Bienestar Animal en Europa, el Reino Unido ha desempeñado un papel muy relevante. En los años 60, la publicación del libro de Ruth Harrison, Animal Machines[4], tuvo un impacto inmediato en la sociedad y alertó sobre las precarias condiciones de vida de los animales de granja, en régimen de ganadería intensiva.

El libro fue un revulsivo y la reacción social que generó determinó que el propio Gobierno inglés ordenara la constitución de una Comisión científica, con la misión de elaborar un informe técnico sobre las condiciones de vida de los animales de granja. Como resultado, se publicó el informe presentado en 1965 por el Prof. Roger Brambell[5] , conocido como "The Brambell Report", en el que se sustanciaba en qué consistía el Bienestar Animal en cinco mínimos o estándares de vida, para asegurar no sólo la integridad física de los animales, sino incluso mental, así como el respeto por su propia idiosincrasia, sus modos de vida y de comportamiento acorde con su naturaleza animal. A partir de esa fecha, se puede decir que el tratamiento de los animales y la defensa de sus intereses y el respeto por su comportamiento (su "cultura"), ha impregnado la visión académica y las políticas públicas a favor de los animales, con un giro que no ha tenido vuelta atrás.

De hecho, como consecuencia del "Brambell Report", el Gobierno británico creó en 1965 el Farm Animal Welfare Advisory Committee, transformado en 1979 en Farm Animal Welfare Commitee, como órgano responsable del cumplimiento y desarrollo de las políticas de Bienestar Animal, sustanciadas en cinco principios que constituyen los estándares de Bienestar Animal y que se conocen con el nombre de las Cinco Libertades ("The Five Freedoms")[6] :

1. La ausencia de hambre y sed: mediante el acceso a agua potable y una dieta para mantener la salud y vigor.

2. La ausencia de la incomodidad: mediante la provisión de un entorno adecuado que incluya cobijo y una zona de descanso cómoda

3. La ausencia de dolor, lesiones o enfermedades: mediante la prevención o el diagnóstico rápido y el tratamiento

4. La libertad de expresar un comportamiento normal: mediante la provisión de un espacio suficiente, instalaciones adecuadas y la compañía de la propia especie del animal.

5. La ausencia de miedo y angustia: asegurando las condiciones y el trato que eviten el sufrimiento mental.

El influjo de estos cinco estándares de Bienestar Animal se refleja en la adopción de los mismos por grandes organizaciones internacionales (World Association for Animal Health, OIE), grupos profesionales integrados por veterinarios y académicos y, desde luego por asociaciones privadas tan prestigiosas como la Royal Society for the Prevention of Cruelty to Animals [7] o Compassion in World Farming [8] , que han asumido el liderazgo de la defensa animal también ante los organismos de la UE. 
Es realmente un papel apasionante el que, en los últimos años, ha desempeñado el Reino Unido en favor de los animales de toda Europa, pero ello también es fruto del influjo de los grandes pensadores británicos que, en medio de una cultura antropocéntrica, muy influenciada en el S.XVII por la filosofía cartesiana, de que los animales no son más que máquinas que reaccionan a los estímulos como simples engranajes, se atrevieron a afirmar, como John Locke (1632-1704), en su obra de 1693 "Some Thoughts

Concerning Education", que los animales tienen sentimientos y que la crueldad ejercida contra ellos es éticamente reprobable, incluso nociva para la educación de los niños, que condicionan su desarrollo moral a la indiferencia ante el sufrimiento de los más débiles y al posible ejercicio de la crueldad en el futuro. Algo, por cierto, sobre lo que ya había advertido Ovidio en el S I d.C.: Saevitia in bruta est tirocinium crudelitatis in homines[9].

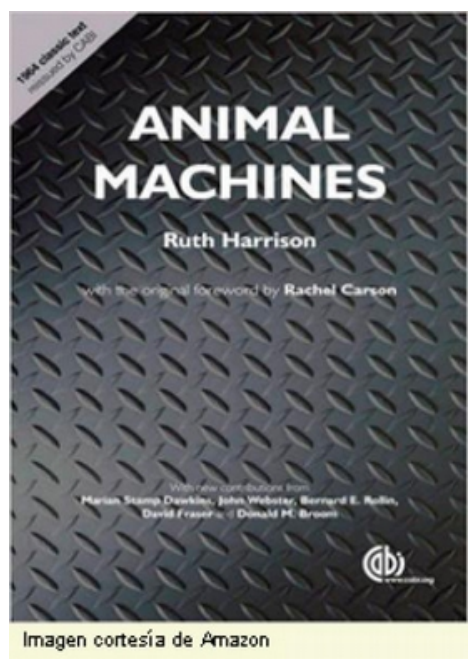

A otro gran filósofo británico, Jeremy Bentham (1748-1832)[10] , le debemos una reflexión que puso en tela de juicio de forma irreversible, la consideración de los animales como "seres inferiores" que el ser humano, por tener raciocinio y capacidad de hablar (los postulados aristotélicos de la superioridad humana), puede dominar y usar a su antojo sin límite alguno. En efecto, la mirada de Bentham se dirigió hacia la capacidad de "sentir" de los animales, lo que los hace, simplemente, iguales a nosotros y, por lo mismo, merecedores de un trato, por lo menos, digno y compasivo.

Desde entonces hasta que la ciencia, otra vez británica, ha declarado a los animales como seres sintientes ("sentient beings"), por ejemplo, recientemente, en la Declaración de Cambridge[11], no dejamos de admirar la contribución del Reino Unido a un mundo mejor y más justo para todos los animales.

El primer libro que leí en inglés, durante un Curso de Lengua y Literatura inglesa en el Jesus College de Cambridge, fue "Animal Farm", de Georges Orwell. Un autor al que admiro y he continuado frecuentando. Aquella primera lectura, me alertó sobre la tiranía, sobre el pensamiento único, sobre la incapacidad para el diálogo, pero a través de unos personajes, los animales de granja, que hablaban y se rebelaban contra los humanos. Una sátira mordaz que me impresionó y me sigue, a día de hoy, pareciendo tan válida como la reflexión del burro "Benjamín" que lee en voz alta a sus compañeros de la granja, el mandamiento convenientemente adaptado por el cerdo "Napoleón": "Todos los animales son iguales, pero algunos son más iguales que otros".

[1] WISCH, R.F., Brief Summary of United Kingdom Animal Law, en Animal Legal \& Historical Center

[2] GIMÉNEZ-CANDELA, T., Seres sintientes

[3] VILLALBA, T., 40 años de Bienestar Animal. Guía de la legislación comunitaria sobre Bienestar Animal (Madrid 2016).

[4] HARRISON R., Animal Machines: The new Factory Farming Industry. Forword by Rachel Carsson (London 1964).

[5] Brambell, R., "Report of the Technical Committee to Enquire into the Welfare of Animals Kept under Intensive Livestock Husbandry Systems”, Her Majesty's Stationery Office (London 1965).

[6] Freedom from Hunger and Thirst: by ready access to fresh water and a diet to maintain full health and vigor. 2 Freedom from Discomfort: by providing an appropriate environment including shelter and a comfortable resting area. 3. Freedom from Pain, Injury or Disease: by prevention or rapid diagnosis and treatment. 4. Freedom to Express Normal Behavior: by providing sufficient space, proper facilities and company of the animal's own kind. 5. Freedom from Fear and Distress: by ensuring conditions and treatment which avoid mental suffering.

[7] La RSPCA fue creada ya en 1924, pero en 1837 la Reina Victoria le otorgó su patronazgo que mantiene la actual monarca británica. Vid. la historia. 
[8] Compassion in World Farming es una de las entidades colaboradoras del Máster en Derecho Animal que tengo la responsabilidad de dirigir. Su profesionalidad y ejemplo de entrega por los animales, son el mejor complemento de la formación de nuestros estudiantes, a los que acogen generosamente cada año en su periodo de prácticas curriculares.

[9] CASTIGNONE, S., Saevitia in bruta est tirocinium crudelitatis in homines.

[10] BENTHAM, J., Introduction to the principles of Morals and Legislation (London 1789) cap. XVII: "...The day may come, when the rest of the animal creation may acquire those rights which never could have been withholden from them but by the hand of tyranny. The French have already discovered that the blackness of skin is no reason why a human being should be abandoned without redress to the caprice of a tormentor. It may come one day to be recognized, that the number of legs, the villosity of the skin, or the termination of the os sacrum, are reasons equally insufficient for abandoning a sensitive being to the same fate. What else is it that should trace the insuperable line? Is it the faculty of reason, or perhaps, the faculty for discourse?...the question is not, Can they reason? nor, Can they talk? but, Can they suffer? Why should the law refuse its protection to any sensitive being?... The time will come when humanity will extend its mantle over everything which breathes..."

[11] The Cambridge Declaration on Consciousness, 7 de julio de 2012 